\title{
ПРОТИВОПОСТАВЛЕНИЕ И ПЕРЕОСМЫСЛЕНИЕ ЕСТЕСТВЕННО-НАУЧНОГО И ГУМАНИТАРНОГО ПОДХОДОВ
}

\author{
В.М. РОЗИН \\ ${ }^{a}$ Федеральное государственное бюджетное учреждение науки Институт философии Российской \\ академии иаук, 109240, Россия, Москва, ул. Гониариая, д. 12, стр. 1
}

\begin{abstract}
Резюме
В статье анализируются ситуация противостояния двух подходов - естественно-научного и гуманитарного и пути преодоления этого противостояния. Характеризуются оба подхода и реконструируются исторические обстоятельства, в которых они появились. Автор выделяет и анализирует три решения, обсуждаемые в настоящее время в научной литературе. Первое решение он называет стратегией конвергенции указанных подходов. Второе решение определяется как стратегия снятия противостояния естественно-научного и гуманитарного подходов. Оно опирается на установку, что наука едина. Третья стратегия авторская. Представление о науке постепенно нащупывается, строится по мере анализа разных типов науки. Кроме того, оказалось, что, с одной стороны, в этих разных типах наук (античной, средневековой, естественной, технической, гуманитарной, социальной и др.) можно выделить инвариантное ядро (своего рода «геном» науки), а с другой - что они как типы различаются структурно. Первая стратегия оценивается автором как формальная, не учитывающая противоположные методологические установки указанных подходов. Недостаток второй он видит в том, что ее сторонники не выявили реальных различий естественных и гуманитарных наук и способов мышления. Третья стратегия - самая сложная, поскольку предполагает анализ становления и функционирования разных типов наук. Но ее реализация позволит истолковать оба подхода как органические и отчасти взаимосвязанные моменты научного исследования и мышления. В рамках подобной стратегии различие естественно-научного и гуманитарного подходов может быть осмыслено, во-первых, как различие форм концептуализации, которые выстраивались в оппозиции друг к другу, во-вторых, как различие характера решаемых проблем, установок исследователей, особенностей научного мышления, областей применения полученных знаний и схем.
\end{abstract}

Ключевые слова: наука, тип, подход, стратегия, мышление, реконструкция, гуманитарный подход, естественно-научный подход, конвергенция, снятие. 
Оппозиция естественных и гуманитарных наук, естественно-научного и гуманитарного подхода в современных исследованиях по философии науки давно уже стала общим местом. И не просто противопоставление, а жесткая полемика, идущая, возможно, от трудов Л.С. Выготского, который в программной работе «Исторический смысл психологического кризиса (методологическое исследование)» писал, что «психологий существуют две, то есть два разных непримиримых типа наук, две принципиально разные конструкции системы знания» (Выготский, 1982, с. 381). Впрочем, здесь Выготский просто продолжает линию В. Дильтея, выступая, правда, не на его стороне, а на противоположной - как сторонник естественно-научного подхода. Эта линия, как известно, продолжается в работах М. Вебера и М. Бахтина. Принимают ее и представители отдельных наук, прежде всего психологии и культурологии.

Вот, например, мнение по этому поводу Б. Ерасова: «Конечно, прежде всего культуроведение - гуманитарная наука, основанная на постижении внутренних закономерностей и структур культуры в ее различных "представительных” вариантах: литература, искусство, язык, мифология, религия, идеология, мораль и наука. В каждом из этих вариантов существует своя система "постижения” тех смыслов и знаний, которые необходимы для понимания текстов, образов, положений и принципов...

Социальная культурология предполагает иную модальность в отношении к культуре, основанном на объективном и аналитическом, не “погруженном", а "отстраненном" взгляде на культурную жизнь общества... Наряду с понимающим вхождением в культуру необходимо и познавательное выяснение функций культуры в обществе. Необходим причинно-следственный анализ, соотнесенный с теоретической концепцией. Последовательное вживание в ту или иную систему культурных образов может означать превращение зрителя или исследователя в приверженца этой системы...» (Ерасов, 1996, с. 5-6, 24).

Позиция Ерасова очень характерная. Он, как и многие современные ученые, считает, что гуманитарная наука ограничивается только постижением (пониманием) культурных явлений, не доходя до теоретических обобщений. Что такое постижение по необходимости субъективно в отличие от объективного изучения в естественных науках. Что гуманитарная наука пользуется «индивидуализирующим методом», позволяющим «воссоздать объект в его подлинности и уникальности», в то время как естественно-научный подход описывает не отдельные объекты, а обобщенные типы, причины и следствия явлений (Там же, с. 23-28).

Осмысление сложившейся ситуации и реакция на нее вылились в три методологические стратегии. Первое решение условно можно назвать стра-

1 «Метод объяснительной психологии, - пишет Дильтей, - возник из неправомерного распространения естественно-научных понятий на область душевной жизни и истории... господство объяснительной или конструктивной психологии, оперирующей гипотезами по аналогии с познанием природы, ведет к последствиям, чрезвычайно вредным для развития наук о духе». Мы «заявляем требование наук о духе на право самостоятельного определения методов, соответствующих их предмету» (Дильтей, 1924, с. 8, 10, 69). 
тегией конвергенции указанных подходов. Ее довольно ясно формулируют А.П. Огурцов и В.В. Платонов в книге «Образы образования. Западная философия образования. ХХ век»: «Верно, что естественные науки, особенно в их классической сциентистской интерпретации, пока что во многом не стыкуются с гуманитарными, но неверно предположение антисциентизма о принципиальной несоизмеримости этих подходов, их закрытости по отношению друг к другу... В целом же их оппозиция эволюционировала в направлении конвергенции, формирования посредствующих звеньев между этими полюсами философского мышления, так что первоначально противостояшие варианты постепенно трансформируются посредством наведения мостов друг к другу... Схождение этих крайностей означает приближение к решению, по-видимому, самой фундаментальной проблематики современной философии» (Огурцов, Платонов, 2004, с. 109, 132).

Если вспомнить, что Дильтей формулировал свою программу в оппозиции к естественно-научной программе, то, по мнению Огурцова и Платонова, возникает сомнение в возможности навести мосты между данными подходами. Можно ли, спрашивается, свести задачи прогнозирования и управления природными процессами, характерные для естественно-научного подхода, к постижению и пониманию, что постулируется в гуманитарном подходе, законы природы - к объяснениям индивидуального поведения (индивидов), природную необходимость - к свободе? «Всякий истинно творческий текст, пишет Бахтин, - всегда есть в какой-то мере свободное и не предопределенное эмпирической необходимостью откровение личности. Поэтому он (в своем свободном ядре) не допускает ни каузального объяснения, ни научного предвидения» (Бахтин, 1979, с. 285). А дальше уже непонятно. «Возникает вопрос, может ли наука иметь дело с такими абсолютно неповторимыми индивидуальностями... не выходят ли они за рамки обобщающего научного познания. Конечно, может» (Там же, с. 287)².

${ }^{2}$ Ср.: «Существует абстрактная позиция третьего, которая отождествляется с “объективной позицией” как таковой, с позицией всякого "научного познания”... В жизни как предмете мысли (отвлеченной) существует человек вообще, существует третий, но в самой живой переживаемой жизни существуем только Я, ТЫ, ОН, и только в ней раскрываются (существуют) такие первичные реальности, как мое слово и чужое слово, и вообще те первичные реальности, которые пока еще не поддаются познанию (отвлеченному, обобщающему), а поэтому не замечаются им» (Бахтин, 1979, с. 348-349). Кажется, предельно ясно, и тем не менее! «Противопоставление гуманитарных и естественных наук, - пишет М. Бахтин, - было опровергнуто дальнейшим развитием гуманитарных наук. Одновременность художественного переживания и научного изучения. Их нельзя разорвать, но они проходят разные стадии и степени не всегда одновременно» (Там же, с. 349). «Гуманитарные науки, - усиливает мысль Бахтина Г.Д. Гачев, - все более прибегают ныне к методам точных наук... идя на сб́лижение с естественными, пользуются методами и результатами последних» (Гачев, 1981, с. 109). Налицо явное противоречие: с одной стороны, Бахтин показывает, что гуманитарное познание не может быть подведено под существующее понятие науки, но с другой - утверждает, что гуманитарное познание подобно естественнонаучному познанию - это тоже наука. 
Второе решение можно назвать стратегией снятия противостояния естественно-научного и гуманитарного подходов. Оно опирается на установку, что наука едина. «Наука одна и едина, - писал Вернадский, - ибо, хотя количество наук постоянно растет, создаются новые, они все связаны в единое научное построение и не могут логически противоречить одна другой» (цит. по: Мирзоян, 2004, с. 90). В.С. Степин полагает, что не имеет смысла противопоставлять естественные, гуманитарные и социальные науки, что либо мы имеем дело с наукой, либо с ненаукой

Позицию В. Степина на снятие проблемы демаркации между естественными и гуманитарно-социальными науками разделяют и составители книги «Синергетическая парадигма. Когнитивно-коммуникативные стратегии современного научного познания» (Киященко и др., 2004). «Резко обогатив свой концептуальный аппарат, - пишут Л. Киященко и П. Тищенко, - синергетика делает изоморфными, легитимно сопоставимыми, традиционно разведенные области естественно-научного и социогуманитарного знания... оставаясь всецело естественно-научной дисциплиной, синергетика смогла включить в свой понятийный потенциал те характеристики, которые в классическую эпоху выражали специфику гуманитаристики. Теперь, чтобы обеспечить собственную специфику, социогуманитарному знанию предстоит ответить на вызов синергетики» (Киященко, Тищенко, 2004, с. 503).

Стоит обратить внимание на выражение «оставаясь всецело естественнонаучной дисциплиной». Оно показывает, что представители второй стратегии идеалом науки считают естествознание. Если это убеждение доводить до логического конца, то приходится признать, что гуманитарные науки, или социальные, или античная наука - это либо вообще не науки, либо же знание в его донаучном состоянии. Примерно так идеологи данного направления и считают. Действительно, ну какая же это наука, если нет эксперимента, математических моделей, однозначных законов, невозможно ничего рассчитать. Конечно, вводя представление о трех этапах развития научной рациональности (классическом, неклассическом и постнеклассическом) и привлекая для обоснования системный подход и синергетику, В. Степин расширяет понятие науки, но при этом он, на мой взгляд, продолжает мыслить согласно логике естественно-научного подходає

Теперь третья, авторская стратегия. Мои исследования показали, что, во-первых, не стоит сразу исходить из того, что мы знаем, что такое наука, а именно что это естествознание. Представление о науке постепенно нащупывается, строится по мере анализа ее разных типов. Во-вторых, оказалось, что, с одной стороны, в этих разных типах науки (античной, средневековой, естественной, технической,

\footnotetext{
${ }^{3}$ Когда вышла моя книга «Особенности и формирование естественных, технических и гуманитарных наук» (Розин, 1989), где я показал, что гуманитарные науки вполне можно подвести под трехслойную схему науки Степина (эмпирический слой, теоретический и слой оснований науки), Вячеслав Семенович очень одобрил это исследование, которое для него служило доказательством, что все типы наук имеют одинаковую структуру.

4 Если мне покажут, что это не так, я с удовольствием возьму свои слова назад.
} 
гуманитарной, социальной и др.) можно выделить инвариантное ядро (своего рода «геном» науки), а с другой - что эти типы различаются структурно.

Укажем сначала некоторые характеристики генома науки. В любой науке имеет место познавательная установка на рациональное объяснение и описание существующих (сложившихся) феноменов (объектов). В любой науке это объяснение и описание осуществляется путем построения «идеальных объектов». Идеальные объекты создаются философами и учеными, которые приписывают изучаемому объекту фиксированные характеристики (свойства), причем таким образом, чтобы возможно было получение непротиворечивых знаний, решение проблем и задач, отображение (в схемах или моделях) изучаемых феноменов. Практически во всех науках существует установка на организацию и систематизацию получаемых знаний (не обязательно в форме теории, а, например, как в гуманитарной науке, путем подведения под единую концепцию). Наука предполагает также определенное осознание, рефлексию (в связи с этим можно ввести представление о «концептуализации» науки); это могут быть как специальные разделы философии и методологии (философия науки), так и формы профессионального самосознания ученых. Наконец, любая наука, даже фундаментальная, ориентирована на решение определенных практических и социальных проблем и поэтому содержит соответствующие установки, которые, правда, с трудом осознаются

Теперь некоторые характеристики структурных различий. Отдельные типы наук создавались в разных исторических и культурных ситуациях для решения разных проблем. Например, самый первый тип науки - «античный» («Начала» Евклида, учения «О плавающих телах» и «рычаге» Архимеда и др.) - формировался в эллинистическую эпоху Античности для решения ряда практических и теоретических проблем (в частности, понадобились математические и технические знания, позволяющие рассчитывать устойчивость кораблей и работу подъемных механизмов). При этом в методологическом отношении Архимед опирался на понятия и принципы, намеченные Аристотелем в «Физике» и «Мтафизике».

Главными здесь были принципы «природы» и ее познания. Пришел к ним Стагирит примерно так. Он ставит своей задачей понять условия эффективного, приводящего к задуманному, практического действия. В качестве такого условия, мешающего или помогающего этому действию, он выделяет естественное изменение (то, что происходит, как он пишет, «по природе»). Это условие, считает Аристотель, задает и обеспечивает разум, поэтому для выявления природных изменений нужно выявлять сущность явлений. В свою очередь, их можно узнать, если правильно мыслить, выявляя «начала» (причины, сущность).

${ }^{5}$ Так, многие представители второй стратегии уверень, что научное изучение объективно и незаинтересованно в практическом отношении. Мол, просто изучаем законы природы. «Цель науки, - пишет Е. Мамчур, - достижение объективного истинного знания». «Но чем бы помешало представителю science studies признание того, что в конечном счете эта заявка у подлинного ученого имеет цель способствовать прогрессу научного исследования, цель которого - познание законов природы» (Мамчур, 2004, с. 45, 222). 
Поскольку природные изменения выглядят как самодвижения, происходящие без участия человека, их двигатель (начало) Стагирит помещает в сами эти изменения. Мысля эти начала, человек может приобщиться к разуму и получить знание природных изменений. На их основе он может построить эффективное практическое действие. Так, если говорить современным языком, был устроен дискурс Аристотеля (Розин, 2017а).

Реально же для получения знаний о природных изменениях Аристотель предлагает наблюдать за самодвижениями (сюда, вероятно, входили и опыты) и строить непротиворечивые знания, описывающие начала. Не исключает он и применение математики, но не придает ему первостепенного значения. В результате объяснение в античном духе получалось, а эффективное действие нет. Архимед за счет математизации достигает эффективности практических действий для двух-трех случаев (законы рычага, плавающих тел, устойчивости кораблей), т.е. не в общем виде.

Если первая особенность античной науки - ее ориентация на аристотелевское понимание природы, то вторая - характер концептуализации. Под концептуализацией науки я понимаю знания о самой науке, понимание и объяснение, ито это такое (анализ показывает, что в разных типах наук концептуализации различны). В античной науке знание о ней создавали главным образом Аристотель и его последователи. Из работ Архимеда видно, что под наукой он понимает непротиворечивое знание о некоторой области природных явлений, полученное на основе начал (определений и постулатов) и опирающихся на них теорем, причем в рамках специальной процедуры доказательства. Интересно, что к науке Архимед, вероятно, относил и построение схем ${ }^{6}$. Действительно, ряд новых геометрических знаний Архимед получает не в теоретическом слое, т.е. на идеальных объектах, а взвешивая модели фигур (эти модели, по моей концепции, он использует в функции схем). Но затем Архимед их вводит в теорию. В предисловии к работе «Квадратура параболы» Архимед пишет, что основную теорему он нашел при помощи механики, но затем также доказал и геометрически, поскольку «указанный метод строгих

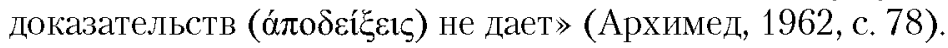

Наличие концептуализации науки не означает невозможность ее изменения. Например, с точки зрения концептуализации пятый постулат «Начал Евклида» о параллельности выглядел как теорема, и его еще в античной науке и позднее неоднократно пытались доказать, опираясь на другие постулаты и определения. Хотя все эти попытки не удались, они существенно способствовали развитию геометрии. В том числе, как известно, эти усилия привели к созданию геометрии Лобачевского. Влияние концептуализаций на науку многообразно, но все же основной механизм - несовпадение реальной науки с ее идеальным образом, заданным концептуализацией, и работа по преодолению подобной несогласованности (Москаева, 1967).

6 Функция схемы следующая. Схемы создаются субъектом (философом, ученым или практиком), позволяя решить стоящие перед ним или обществом проблемы. Они задают новую реальность, позволяя понимать, что происходит, и по-новому действовать (см.: Розин, 2011). 
Учтем теперь, что в античной культуре «геном науки», содержащий рассмотренные здесь моменты (установки на построение идеальных объектов и непротиворечивого знания, на получение знаний для расчетов, на концептуализацию), только складывался. С точки зрения ретроспективы античная наука была еще недостаточно дифференцирована с философией (многие античные ученые считали себя философами), концептуализация науки слабо отрефлексирована, ориентация науки на решение проблем и вызовов времени не осознавалась. Достаточно четко осознавались установки на построение непротиворечивых знаний, поиск истины (причин явлений), на специфический способ получения и организации научных знаний (построение начал и доказательства теорем).

В новое время геном науки устанавливается заново в связи со сменой целого, а именно культуры и характера жизни человека. Если в Средние века целое задавали вера в христианского Бога и задачи спасения человека (переделка «ветхого» человека), то в Новое время на первый план выходит культура, не исключающая Бога, но отводящая ему роль простой первопричины творения, и только, а двумя главными задачами выступают построение «царства человека» и «овладение природой». Вспомним раздел в книге Ф. Бэкона «Великое восстановление наук»: «афоризмы об истолковании природы и царстве человека».

Говоря о царстве человека, Бэкон, по сути, задает новый смысл жизни человека в культуре: власть над природой, дающая человеку, с одной стороны, могущество, с другой - разнообразные блага. В «Новом органоне» Бәкон утверждает, что подлинная цель науки «не может быть другой, чем наделение человеческой жизни новыми открытиями и благами», а «власть человека над вешами заключается в одних лишь искусствах и науках». «усть, - пишет он, - человеческий род только овладеет своим правом на природу, которая назначила ему божественная милость, и пусть ему будет дано могущество» (Бэкон, 1935, с. 147, 193).

Под природой Бэкон понимает достаточно сложное образование, подготовленное ренессансными размышлениями философов и ученых. Во-первых, именно природа, но созданная не Творцом, а человеком, является источником новых благ и могущества человека. Во-вторых, устройство такой природы человек должен описать в новой науке (позднее она получила название «естественной», «естествознания»). В-третьих, в этом случае природа не просто естественное образование (точка зрения Аристотеля), а образование естественно-искусственное.

«Но никто, - утверждает Бэкон, - не может придать данному телу новую природу или удачно и целесообразно превратить тело в новое, пока он не будет хорошо знать об изменении и превращении тела». «Итак, наше требование и предписание относительно истинной и совершенной аксиомы знания состоит в том, чтобы была открыта другая природа... Но эти два требования относительно действенного и созерцательного суть одно и то же. Что в Действии наиболее полезно, то в Знании наиболее истинно» (Там же, с. 197, 200). Бэкон пишет, что человека интересует не природа, до которой человек не может добраться, например, в звездах или недрах земли, а «природа, связанная и стесненная, когда искусство и служение человека выводит ее из обычно- 
го состояния, воздействует на нее и оформляет ее» (Там же, с. 96). При этом под искусством он в данном случае понимает «новую магию» или инженерию.

Но это была одна линия истолкования природы. В работах Галилея к ней добавляется другая линия. Он природу понимает как «написанную на языке математики», а также (что не противоречит идее «природы, стесненной искусством») как приведенную техниески к новому состоянию, соответствуюиему требованиям данного математического языка. Совместно эти характеристики обещали не просто овладение природными явлениями, но и управление ими, не только использование изменений и превращений тел, но и получение от этих превращений нужного человеку практического эффекта. Именно эти установки на управление и ожидаемый эффект и схватывались позднее в понятии «закон природы». Если суммировать, то природе человек Нового времени приписывает три основные характеристики: она является условием новой культурной целостности (задает новый смысл жизни), трактуется как онтология для новой еще не созданной науки, должна быть описана в математике и приведена технически в состояние, изоморфное данному описанию.

Перечисленные здесь характеристики концептуализации задавали совершенно другие, чем в Античности, образ и строение науки. Такой науки еще не было. Первый образец естественной науки, как известно, создал Галилей.

Программа построения гуманитарных наук (первоначально их называли «науками о культуре», «науками о духе»), как уже отмечалось, создавалась в оппозиции к концептуализации естественных наук. Это опять был ответ на новое целое (уже в рамках новоевропейской культуры) и новые проблемы. Выяснилось, что естественно-научный подход удается распространить не на все; в частности, человек, история, культура не поддавались математизации, относительно этих феноменов не получался и галилеевский эксперимент. Например, в психологии постановка такого эксперимента предполагала, что именно психика выступала фактором, определяющим идеализированное поведение человека, и именно ее нужно было элиминировать в эксперименте. Кроме того, развитие новоевропейской культуры выявило роль личности, которая часто вела себя не как все (массы), а также значение творчества и взаимоотношений людей, совершенно не укладывающихся в понятие закона природы. Все это и ряд других обстоятельств обусловили выдвижение новой программы концептуализации науки.

В книге, посвященной особенностям гуманитарного исследования и науки (Розин, 2009), я показываю, что гуманитарное познание в лучших своих образцах имеет все черты нормальной науки, а именно опирается на факты, отображает реальность методом конструирования идеальных объектов, если нужно, оформляется в теорию. Это, так сказать, инвариантные характеристики науки (как генома), одинаковые для естествознания и гуманитарного подхода. Специфика гуманитарной науки в другом.

Гуманитарная наука изучает не природные явления, а такие, которые имеют отношение к человеку (сам человек, произведения искусства, культура и пр.). Гуманитарные знания используются не с целью прогнозирования и управления, а для понимания или гуманитарного воздействия, например педа- 
гогического. Гуманитарное познание разворачивается в пространстве разных точек зрения и подходов, в силу чего гуманитарий вынужден позиционироваться в этом «поле», заявляя особенности своего подхода и ви́дения. Хотя начинается гуманитарное познание с истолкования текстов и их авторского понимания, но затем гуманитарий переходит к объяснению предложенного им истолкования, что предполагает изучение самого явления. Наконец, гуманитарное научное познание - не только познание, но одновременно и взаимоотношение ученого и изучаемого явления. Одна из важных особенностей гуманитарного мышления состоит в том, что, изучая, гуманитарий движется одновременно в двух пространствах - в одном он действует как нормальный ученый (формулирует и решает проблемы, создает идеальные объекты, описывает факты и пр.), в другом общается с изучаемым субъектом как личностью (предоставляет ему голос, выслушивает, старается понять, что-то обьясняет и т.д.; см. мое исследование «Две жизни А.С. Пушкина»: Розин, 2009, с. 108-127).

Таким образом, реализация третьей стратегии предполагает анализ становления и функционирования науки как культурно-исторического феномена и реконструкцию ее разных типов. Наука здесь рассматривается в более широком контексте культуры: с одной стороны, она характеризуется с точки зрения вызовов и проблем времени, с другой - анализируется использование ее продуктов (знаний, схем, идеальных объектов) в различных практиках (инженерии, педагогике, управлении и др.). Чтобы понять особенности концептуализации науки, в качестве единицы анализа берется не просто наука, а целое «наука - философия», «наука - методология». Не менее важен и такой план, как анализ научного мышления: анализ познавательных ситуаций, установок исследователей, особенностей идеальных объектов и онтологии, характер организации научных знаний (концепции, теории, собрания и др.), особенности обоснования научных построений и пр.

В качестве разных естественно-научный и гуманитарный подходы в ряде случаев вполне могут быть реализованы в одном научном исследовании или даже в определенном типе наук. Пример первого случая - исследования 3. Фрейда, а второго - социология.

Как я показываю в книге «Психология в фокусе методологии и философии науки» (Розин, 2017б), представления, которые формулирует Фрейд, формировались под действием, по меньшей мере, двух факторов: реализации физикалистских ценностей и философско-психологических установок. В физикалистской онтологии центральной выступила идея «взаимодействия»: полагались два самостоятельных объекта (два «аффекта», «переживания», две «душевные группировки») и силы взаимодействия, действующие между ними («сопротивление», «оттеснение»). В философско-психологической онтологии каждый из этих объектов (душевных группировок) трактовался как вторая и третья самостоятельные «личности» в человеке; соответственно силы взаимодействия переосмыслялись как «конфликт» двух личностей, «забывание», сопротивление одной из них.

Фрейд пытался определить характер «защемленных» аффектов («оторвавшихся» душевных группировок) с тем, чтобы знать, на какие признаки поведения 
пациента или его высказывания нужно ориентироваться психотерапевту для постановки правильного диагноза и дальнейшего лечения. Одновременно Фрейд стремился создать объяснение всех наблюдаемых им явлений по естественно-научному образцу: построить идеальный объект, полностью имитировать на нем функционирование и поведение объекта (т.е. задать механизм), объяснить согласно логике построенного механизма все явления, наблюдаемые в психотерапевтической практике. Можно реконструировать следующие логические шаги построения первой теории Фрейда.

Судя по всему, центральной идеей, положенной Фрейдом в основание подобного механизма (идеального объекта), послужило представление о взаимодействующих в человеке самостоятельных конфликтных личностях (душевных группировках), которые позднее в его теории преврашаются в инстанции психики. Второе соображение, касающееся строения этого механизма, было получено из скрещивания идеи катарсиса и факта сопротивления. Фрейд приходит к мысли, что, если определенное переживание (душевная группировка) не пережито (не отреагировано), поскольку противоречит культурным нормам сознания, оно уходит из сознания, забывается и одновременно мешает текущей психической активности. Чтобы устранить эту помеху (снять психическую травму), необходимо в какой-либо форме такое переживание пережить, провести через сознание. Представления о конфликте культуры и общества, одной личности с другой были отчасти конструктивными, отчасти эмпирическими. Совмещая и объективируя все эти представления и идеи, Фрейд вводит понятия о бессознательном и цензуре (ее обеспечивала предсознательная инстанция), а также идею вытеснения.

Что такое на данном этапе построения идеального объекта «бессознательное»? С одной стороны, область психики, где действует «защемленная» (вытесненная) личность, о которой сам человек ничего не знает, которую он не осознает. Именно с этой странной «личностью» имели дело Брейер и Фрейд, когда вводили больного в гипноз и спрашивали его об исходной травме. С другой стороны, бессознательное - это та же личность (душевная группировка), находящаяся в конфликте с другой личностью (она отождествляется с обычным сознанием) и одновременно стремящаяся к ней, поскольку только так она может реализовать себя. Трактовка инстанций психики не только как составляющих, подсистем и особых сил (стремление к реализации, запрет, вытеснение), но и как самостоятельных личностей позволяла Фрейду рассматривать соответствующие содержания инстанций в качестве особых высказываний, текстов. В этом плане все психические феномены получали в теоретической конструкции Фрейда двоякую трактовку: как особые конфликтные силь и суиности (желания, влечения) и как мысли, высказывания, которые нужно было адекватно понять и расиифровать. И вот почему.

Фрейд предполагал, что бессознательное как личность, чтобы реализовать себя, вынуждено хитрить, маскировать свои истинные мысли и желания. Поэтому, прорываясь в сознание (когда действие цензуры ослабевает), бессознательное реализует себя, так сказать, в форме инобытия: оно высказывается на эзоповском языке; в плане же феноменальном предстает в сознании как 
другое, не похожее на себя явление. Следовательно, возникает задача анализа сознания с целью преодоления маскировки, расшифровки и толкования образов и высказываний, с тем чтобы понять, какие же бессознательные структуры стремятся к реализации. Как мы видим, эта вторая трактовка психики может быть понята только в рамках гуманитарного подхода.

Нужно отметить еще один важный момент: на данном этапе конструирования идеального объекта бессознательными по содержанию могли быть любые вытесненные желания и влечения, лишь бы они удовлетворяли требованию конфликтности и сознание могло быть истолковано как условие реализации бессознательного. Определение и расшифровка бессознательных влечений зависели, прежде всего, от искусства психотерапевта. Приходилось перебирать и анализировать большое число случаев из жизни пациента, прежде чем психотерапевту удавалось нащупать ситуацию, вызвавшую психическое нарушение. При этом до конца психотерапевт так и не мог быть уверен, что найденное им звено как раз то, которое позволит вытянуть всю цепь последовавших у пациента нарушений в деятельности психики и организма. Таким образом, здесь тоже присутствовал гуманитарный момент.

Конструкция бессознательного все же не позволяла Фрейду однозначно сузить поле поисков психической травмы, к чему он, безусловно, стремится, поскольку ориентируется на физикалистский идеал науки и поиск механизма психики. Тогда Фрейд предпринимает еще один кардинальный шаг: старается превратить свою теоретическую конструкцию в полный механизм. Чтобы снять многозначность и неопределенность в поиске бессознательных структур (вытесненных желаний, влечений), Фрейд приписывает этим структурам строго определенное значение, а именно трактует их как сексуальные влечения (инстинкты).

Выбор сексуальности как значения бессознательного был отчасти случайным (подсказка Шарко), отчасти же действительно давал решение проблем, стоящих перед (рейдом. Во-первых, сексуальность легко интерпретировалась энергетически, тем самым идеальный объект (психика) находил свое место в природе, понимаемой физикалистски. Во-вторых, этот же объект можно было интерпретировать в ценностном и культурном планах (в качестве влечений, входящих в конфликт с нормами культуры), т.е. отнести к природе, понимаемой уже как культура. В-третьих, Фрейд получал четкое правило дешифровки (интерпретации) интересующих его феноменов сознания: истерии, сновидений, описок, юмора и т.д. Они теперь должны были сводиться к сексуальным влечениям, вытесненным в бессознательное.

Поистине гениальной была идея отнесения всех психотравм в детство. Как известно, Фрейд утверждает, что основные психические проблемы у человека возникают именно в этот период. Приняв такое объяснение, пациенты в значительной степени перестают сопротивляться, поскольку того, что было в детстве, они не помнят. Отнесение конфликтов к детству, с одной стороны, резко сужало область возможных травматических ситуаций и, следовательно, время их поиска, с другой - позволяло на порядок снизить сопротивление клиента. Действительно, взрослый человек, как правило, сопротивляется 
относящимся к его текущей жизни интерпретациям заболевания, с которыми он по какой-либо причине не согласен. Однако того, что конкретно с ним происходило в детстве, он часто не помнит или помнит смутно, поэтому легче принимает даже весьма сомнительные интерпретации событий, если утверждается, что последние имели место в детстве. Наконец, сведение же всех детских конфликтов к комплексам Эдипа или Электры позволяло Фрейду, во-первых, еще более сузить область потенциальных травматических ситуаций, во-вторых, придать им четкие операциональные значения, связанные с основными уже выявленными отношениями (конфликта, сопротивления, сексуальности).

Проделав все эти сведе́ния и упрощения (так дело выглядит в нашей реконструкции; сам Фрейд, естественно, был уверен, что движется к уяснению природы психики), создатель психоанализа делает последний шаг. Он конструирует психику как объект естественно-научной теории. Бессознательное теперь - это сексуальная энергия и инстинкты. Бессознательное является основным психическим процессом; то, что сексуальные энергия и инстинкты не осознаются, отступает на второй план, становится одним из моментов. Сознание теперь - это не столько сознание, сколько необходимое условие реализации бессознательного. На пути реализации бессознательного стоит предсознательное, или цензура. С одной стороны, эта инстанция психики работает как фильтр, с другой - как активная сила, как сопротивление. Отношения между бессознательным и предсознательным напоминают взаимодействие противоположных сил.

Конечно, все эти отношения и сама конструкция психики как идеального объекта были получены не сразу, приходилось возвращаться к исходной ситуации (помощи больному и объяснению того, что получается) и заново согласовывать одни элементы конструкции с другими. Однако, думаю, общая логика были именно такова (см.: Розин, 2017б).

Всю эту работу можно рассмотреть, с одной стороны, как упрощение представлений о психике, а с другой - как конструирование идеального построения, удовлетворяющего механизмическим естественно-научным представлениям. Если бы Фрейд мыслил подобно Галилею, то следующим логическим шагом в его деятельности была бы постановка эксперимента, позволяющего установить соответствие слоя идеальных объектов слою реальных объектов (реальному поведению человека). Однако Фрейд, несмотря на свое физикалистское мировоззрение, мыслит скорее в гуманитарном плане, где подобное соответствие устанавливается не в эксперименте, а сразу в исходном пункте изучения за счет реализации ценностного отношения к самой практике. С самого начала он исходит из представления о конфликте между человеком и обществом и частично - между врачом и пациентом (феномен сопротивления); он создает такие интерпретации феноменов сознания пациента и ведет осознание им своих проблем по такому пути, которые полностью отвечают представлениям Фрейда об устройстве психики. Получается, что теоретические представления поддерживают и направляют практику, а практика - теоретические представления. 
Вывод очевидный: в творчестве Фрейда реализуются сразу два подхода, естественно-научный и гуманитарный 7.

Вторую ситуацию можно проиллюстрировать на примере одной концептуализации социологии. «Сейчас, - утверждает В.Г. Федотова, - существует некоторая тенденция отказа от научного доминирования в социальной сфере и тенденция критики науки, критики во многом справедливой. Подчеркивается значение научно-гуманитарного и вненаучного социального знания. Их бо́льшая непосредственность, понятность для неспециалистов, связь с обыденно-практическим сознанием вызывает естественное доверие к такому типу знания. Однако социальные науки несут ответственность перед людьми за состояние социальной жизни, ибо их цель заключается не только в объективном познании, но и в нахождении путей социально необходимых преобразований. Требование понятности, доступности для обсуждения заменяется другим - уметь раскрыть социальные механизмы, дать возможность их использовать, осуществить не только регулятивно-консультативную, но и познавательно-преобразующую, даже технологическую функцию. Социальные науки гуманитарно-адекватны, если выполняют эти задачи. Например, экономические науки проявят свою гуманитарную адекватность, если не только выразят экономические устремления людей, но и найдут механизмы и способы реализации этих устремлений на основе объективных экономических законов» (Федотова, 2000, с. 136).

В результате всех этих размышлений Федотова приходит к мысли, что «социальный подход» должен строиться на взаимодействии двух других подходов - естественно-научного и гуманитарного. «Речь идет, - пишет она, - о взаимодействии социальных и гуманитарных наук, то есть об одновременной работе двух программ. Одна анализирует цели и ценности субъекта, другая выявляет закономерности, которые могли бы привести к достижению этих целей. Первая ориентирована на “очеловечивание”, вторая - на “овещнение”... Попытка строить третью, “интегрирующую”, неверна, хотя бы потому, что обе программы имеют разнонаправленные векторы, взаимоотрицают друг друга» (Там же, с. 139).

Проблема конвергенции естественно-научного и гуманитарного подходов в рамках второй и третьей стратегий предполагает, во-первых, новую концептуализацию науки, снимающую указанную оппозицию подходов, во-вторых, разворачивание нового цикла исследований науки (под новую концептуализацию), в том числе в рамках третьей стратегии становится необходимой реконструкция становления и функционирования разных типов наук.

7 Особенно ясно гуманитарный характер исследования Фрейда проявлялся при истолковании им сновидений, которые он понимал как нуждающиеся в истолковании и расшифровке тексты замаскированных вытесненных бессознательных влечений. Для расшифровки сновидений Фрейд прикладывает к своим теоретическим штудиям соответствующий сонник (своеобразный дешифратор) (Фрейд, 2005). 


\section{Литература}

Архимед. (1962). Квадратура параболы. В кн. Архимед, Сочинения (с. 77-95). М.: Физматтиз. Бахтин, М. (1979). Эстетика словесного твориества. М.: Искусство.

Бэкон, Ф. (1935). Новьй органон. Л.: Соцэкгиз. Ленинградское отделение.

Выготский, Л. С. (1982). Исторический смысл психологического кризиса (методологическое исследование). В кн. Л. С. Выготский, Собрание сочинений (в 6 т., т. 1, с. 291-436). М.: Педагогика.

Гачев, Г. Д. (1981). О возможном содействии гуманитарных наук развитию естественныт. В кн. методологиеские проблемы взаиодействия общественных, естественных и технических наук (с. 109-126). М.: Наука.

Дильтей, В. (1924). Описательная психология. М.: Русский книжник.

Ерасов, Б. С. (1996). Социальная культурология. М.: Аспект-пресс.

Киященко, Л. П. [и др.]. (2004). Синергетическая парадигма. Когиитивно-коммуникативиье стратегии современного науиного познания. М.: Прогресс-Традиция.

Киященко, Л., Тищенко, П. (2004). Опыт предельного стратегия «разрешения» парадоксальности в познании. В кн. Вызов познанию: Стратеzии развития науки в современном мире (с. 232-258). М.: Наука.

Мамчур, Е. А. (2004). Объективность науки и релятивизм: (К дискуссиям в современной эпистемологи). М.: Мысль.

Мирзоян, Э. (2004). Единство естествознания как проблема истории и философии науки. В кн. Възов познанию: Стратегии развития науки в современном мире (с. 86-103). М.: Наука.

Москаева, А. С. (1967). Математика и философия. В кн. Проблемы исследования структуры науки (с. 165-173). Новосибирск.

Огурцов, А. П., Платонов, В. В. (2004). Образы образования. Западная философия образования. $X X$ век. СПб.: Изд-во Русского Христианского гуманитарного университета.

Розин, В. М. (1989). Особениости и формирование естествениых, техпиеских и гуманитариых наук. Красноярск: Изд-во Красноярского университета.

Розин, В. М. (2009). Особенности дискурса и образцы исследования в гуманитарной науке. М.: ЛИБРОКОМ.

Розин, В. М. (2011). Введение в схемологюю. Схемь в философии, культуре, науке, проектировании. М.: ЛИБРОКОМ.

Розин, В. М. (2017а). Природа: Понятие и этапы развития в европейской культуре. М.: ЛЕНАНД. Розин, В. М. (2017б). Психология в фокусе методологии и философии науки. М.: URSS.

Федотова, В. Г. (2000). Основные исследовательские программы социально-гуманитарных наук. В кн. В. Г. Федотова, Анархия и порядок. М.: URSS.

Фрейд, 3. (2005). Толковапие сиовидений. М./Минск: АСТ/Харвест.

Розин Вадим Маркович - главный научный сотрудник, Институт философии РАН, доктор философских наук, профессор.

Сфера научных интересов: методология, психология, философия.

Контакты: rozinvm@gmail.com 


\title{
Contradiction and Rethinking of Natural and Humanitarian Approaches
}

\author{
V.M. Rozin ${ }^{\mathrm{a}}$ \\ aInstitute of Philosophy, Russian Academy of Sciences, 109240, Moscore, Gonchamaya st., 12/1
}

\begin{abstract}
The article analyzes the situation of confrontation between two approaches - the natural and humanitarian and the ways of overcoming this confrontation. Both approaches are characterized and the historical circumstances in which they have appeared are reconstructed. The author singles out and analyzes the three solutions currently being discussed in the scientific literature. The first solution he calls the strategy of convergence of these approaches. The second decision is defined as a strategy to remove the confrontation between the natural-science and humanitarian approaches. It relies on the establishment that science is one. The third strategy is authoring. His studies of science and its origin have shown that when studying it, one should not immediately proceed from the fact that we know what science is, namely, it is natural science. The idea of science is gradually groping, being built as the analysis of different types of science. In addition, it was found that, on the one hand, these different types of Sciences (ancient, medieval, natural, technical, humanitarian, social, etc.) can distinguish the invariant core (a sort of "gene" of science), and on the other - that they as types differ structurally. The first strategy is estimated by the author as formal, not taking into account the opposite methodological settings of these approaches. He sees the disadvantage of the second in the fact that its followers did not reveal real differences in the natural and human sciences and ways of thinking. The third strategy is the most difficult, since it involves analysis of the formation and functioning of different types of sciences. But its implementation will allow us to interpret both approaches as organic and partly interrelated moments of scientific research and thinking. As part of this strategy the distinction of science and humanitarian approaches can be comprehended in the first place, the diversity of forms of conceptualization, which, indeed, were built in opposition to each other, and secondly, the difference in the nature of problems to be solved, researchers' attitudes, characteristics of scientific thinking, areas of application of the acquired knowledge and schemes.
\end{abstract}

Keywords: science, type, approach, strategy, thinking, reconstruction, humanitarian approach, natural-science approach, convergence, removal.

\section{References}

Archimedes. (1962). Kvadratura paraboly [Quadrature of the parabola]. In Archimedes, Sochineniya [Collected works] (pp. 77-95). Moscow: Fizmatgiz. (in Russian)

Bacon, F. (1935). Noryi organon [Novum Organum]. Leningrad: Sotsekgiz. (in Russian)

Bakhtin, M. (1979). Estetika slovesnogo tvorchestva [Aesthetics of verbal creativity]. Moscow: Iskusstvo. Dilthey, W. (1924). Opisatel'naya psikhologiya [Descriptive psychology]. Moscow: Russkii knizhnik. Erasov, B. S. (1996). Sotsial'naya kul'turologiya [Social culturology]. Moscow: Aspekt-press. (in Russian) Fedotova, V. G. (2000). Osnovnye issledovatel'skie programmy sotsial'no-gumanitarnykh nauk [Main research programs of social and humanitarian sciences]. In V. G. Fedotova, Anarkhiya i poryadok [Anarchy and order]. Moscow: URSS. (in Russian) 
Freud, S. (2005). Tolkovanie snozidenii [Interpretation of dreams]. Moscow/Minsk: AST/Kharvest.

Gachev, G. D. (1981). O vozmozhnom sodeistvii gumanitarnykh nauk razvitiyu estestvennykh [On the possible contribution of the humanities to the development of natural sciences]. In Metodologicheskie problemy vzaimodeistviya obshchestvennykh, estestvennykh i tekhnicheskikh nauk [Methodological problems of interaction of social, natural and technical sciences] (pp. 109-126). Moscow: Nauka. (in Russian)

Kiyashchenko, L. P. [et al.]. (2004). Sinergeticheskaya paradigma. Kognitiono-kommunikationye strategii sozremennogo nauchnogo poznaniya [Synergetic paradigm. Cognitive-communicative strategies of contemporary scientific cognition]. Moscow: Progress-Traditsiya. (in Russian)

Kiyashchenko, L., \& Tishchenko, P. (2004). Opyt predel'nogo strategiya "razresheniya" paradoksal'nosti v poznanii [Experience of the ultimate - the strategy of "solving" paradox in cognition]. In Vyzov poznaniyu: Strategii razvitiya nauki v sozremennom mire [Challenge to knowledge: the strategy of the development of science in the modern world] (pp. 232-258). Moscow: Nauka. (in Russian)

Mamchur, E. A. (2004). Ob"ektivnost' nauki i relyativizm: (K diskussiyam v sovremennoi epistemologii) [Objectivity of science and relativism: (To discussions in modern epistemology)]. Moscow: Mysl'.

Mirzoyan, E. (2004). Edinstvo estestvoznaniya kak problema istorii i filosofii nauki [Unity of natural science as a problem of history and philosophy of science]. In Vyzov poznaniyu: Strategii razvitiya nauki v sozremennom mire [Challenge to knowledge: the strategy of the development of science in the modern world] (pp. 86-103). Moscow: Nauka. (in Russian)

Moskaeva, A. S. (1967). Matematika i filosofiya [Mathematics and philosophy]. In Problemy issledovaniya struktury nauki [Problems in the study of the structure of science] (pp. 165-173). Novosibirsk. (in Russian)

Ogurtsov, A. P., Platonov, V. V. (2004). Obrazy obrazovaniya. Zapadnaya filosofiya obrazovaniya. XX vek [The images of education. Western philosophy of education. The twentieth century]. Saint Petersburg: Russkii Khristianskii gumanitarnyi universitet. (in Russian)

Rozin, V. M. (1989). Osobennosti i formirovanie estestvennykh, tekhnicheskikh $i$ gumanitamykh nauk [Features and formation of natural, technical and human sciences]. Krasnoyarsk: Krasnoyarskii universitet. (in Russian)

Rozin, V. M. (2009). Osobennosti diskursa i obraztsy issledovaniya v gumanitarnoi nauke [Specifics of the discourse and patterns of research in the humanities]. Moscow: LIBROKOM. (in Russian)

Rozin, V. M. (2011). Vvedenie o skhemologiyu. Skhemy v filosofii, kul'ture, nauke, proektirovanii [Introduction to schemology. Schemes in philosophy, culture, science, design]. Moscow: LIBROKOM. (in Russian)

Rozin, V. M. (2017a). Priroda: Ponyatie i etapy razvitiya v evropeiskoi kul'ture [Nature: The concept and stages of development in European culture]. Moscow: LENAND. (in Russian)

Rozin, V. M. (2017b). Psikhologiya o fokuse metodologii i filosofii nauki [Psychology is in the focus of methodology and philosophy of science]. Moscow: URSS.

Vygotsky, L. S. (1982). Istoricheskii smysl psikhologicheskogo krizisa (metodologicheskoe issledovanie) [Historical meaning of the psychological crisis (methodological study)]. In L. S. Vygotsky, Sobranie sochinenii [Collected works] (Vol. 1, pp. 291-436). Moscow: Pedagogika.

Vadim M. Rozin - chief research fellow, Institute of Philosophy, Russian Academy of Sciences, D.Sc., professor.

Research area: methodology, psychology, philosophy.

E-mail: rozinvm@gmail.com 